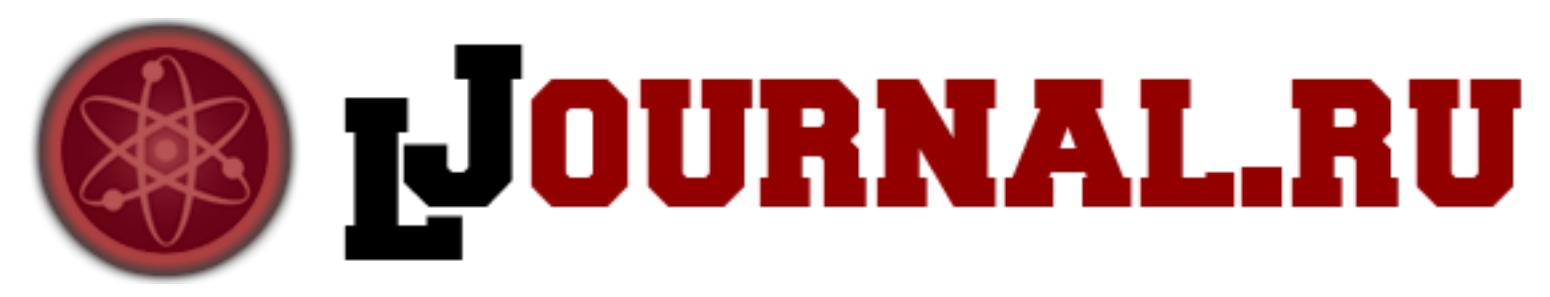

Борисов В. А., Силютина М. В., Таранина О. Н., Тестова С. Г., Мельников А. А., Покачалова М. А. ГБОУ ВПО «Воронежский государственный медицинский университет им. Н.Н. Бурденко» Министерства здравоохранения Российской Федераиии Воронеж, Россия

doi: 10.18411/1j2016-1-01

\title{
Распространенность депрессивных расстройств у лиц старших возрастных групп при хронической сердечной недостаточности
}

\section{Введение}

Увеличение доли лиц пожилого возраста считают одной из главных причин высокой распространенности ХСН в экономически развитых странах [1]. Распространенность ХСН увеличивается с возрастом. При этом особенностью $\mathrm{XCH}$ у лиц старших возрастных групп является наличие нескольких этиологических факторов, приводящих к ее развитию. Главными причинами $\mathrm{XCH} \mathrm{у} \mathrm{лиц} \mathrm{этой} \mathrm{возрастной} \mathrm{категории} \mathrm{являются} \mathrm{ишемическая} \mathrm{болезнь} \mathrm{сердца,}$ артериальная гипертензия и их сочетание. Также причинами могут быть сахарный диабет и ожирение в сочетании с кардиоваскулярной патологией.

Одновременное наличие нескольких заболеваний у лиц старших возрастных групп изменяет их клиническую картину, что затрудняет диагностику, выбор оптимального лечения и приводит к снижению качества жизни. Часто у таких пациентов наблюдается низкая приверженность к лечению. В ряде случаев это может быть обусловлено наличием тревожно-депрессивных расстройств у данной категории пациентов. 
Больше половины пациентов старших возрастных групп с ХCH имеют различные тревожно-депрессивные расстройства. [2]. Частота их зависит от тяжести течения $\mathrm{XCH}$.

В настоящее время в большинстве исследований подтверждено отрицательное действие тревожно-депрессивных расстройств на прогноз ишемической болезни сердца $[3,4]$, являющейся одной из главных причин хронической сердечной недостаточности.

Одной из серьезных проблем у данной категории пациентов является наличие маскированных депрессий. Заподозрить у пациента депрессию можно при наличии следующих неспецифичных жалоб: снижение настроения, выраженная утомляемость, упадок сил. Характерным является и цикличность течения соматических расстройств. Нередко наблюдается несоответствие между объективным статусом и субъективным самочувствием больного: превалирует субъективная симптоматика. При наличии тревожно-депрессивных расстройств характерным является неэффективность терапии соматического заболевания.

\section{Методика исследования}

В исследовании приняли участие 70 пациентов в возрасте 60-87 лет. Из них пациентов пожилого возраста было 60 человек, а старческого возраста - 10 человек. У всех пациентов была хроническая сердечная недостаточность I-II ФК по NYHA.

Цель исследования: определение распространенности тревожнодепрессивных расстройств у пациентов пожилого и старческого возрастов, страдающих хронической сердечной недостаточностью. Для этого мы использовали две психометрические шкалы: HADS и шкала Бэка.

\section{Обсуждение результатов}

При проведении диагностики психологического состояния по скринирующей шкале HADS были получены следующие результаты: клинически выраженная тревога/депрессия была выявлена у 51,4\% (36 человек) обследованных. Причем выраженная тревога/депрессия у лиц старческого 
возраста наблюдалась у 60\% обследованных (6 человек), а у лиц пожилого возраста - у 50\% (30 человек). Такие результаты сопоставимы с данными литературы об увеличении психосоматических заболеваний в зависимости от возраста.

Группу пациентов с клинически выраженной тревогой/депрессией мы протестировали по шкале Бэка, которая является более точной диагностической шкалой для определения депрессии. В результате тестирования мы получили следующие результаты. Среди лиц старческого возраста у 33,3\% (2 человека) больных наблюдалась легкая степень депрессии, у 33,3\% (2 человека) больных наблюдалась тяжелая степень депрессии. Среди лиц пожилого возраста у 26,7\% (8 человек) обследованных наблюдалась депрессия средней тяжести; у 60\% (18 человек) выявлена тяжелая степень депрессии.

Таким образом, из 70 обследованных пациентов старших возрастных групп у 30 (42,86\%) человек наблюдалась депрессия. При этом тяжелая депрессия у лиц пожилого возраста встречалась чаще, чем у пациентов старческого возраста. Это свидетельствует о высоком риске развития ассоциированных клинических состояний у лиц пожилого возраста.

Bce обследуемые нами пациенты наблюдались в поликлиниках г. Воронежа. На приеме у врачей они жаловались на наличие отеков, одышки, головные боли на фоне повышения артериального давления. Часть пациентов предъявляли жалобы на боли в суставах. При детальном расспросе нами было выявлено, что у большинства пациентов имелись признаки депрессии. Они предъявляли жалобы на подавленное настроение, общую слабость, упадок сил, чувство тревоги, трудность в принятии решений. Часть больных жаловалась на плохой сон и снижение концентрации внимания. При этом, ни у кого не было диагноза депрессии. Данный факт может быть связан с неспецифичностью жалоб пациентов и гиподиагностикой, связанной с отсутствием понимания врачом важности выявления тревожно-депрессивных расстройств у данной категории пациентов. 


\section{Заключение}

В ходе исследования получены данные о достаточно широкой распространенности тревожно-депрессивных расстройств у пациентов старших возрастных групп, страдающих ХCH.

Проблема сочетания хронической сердечной недостаточности с тревожнодепрессивными расстройствами является социально значимой, требующей ранней диагностики и своевременной адекватной терапии.

Именно поэтому, считаем необходимым включать в алгоритм исследования пожилого пациента на уровне участкого врача-терапевта или врача общей практики шкалу HADS. Затем, при выявлении признаков клинически выраженной тревоги/депрессии, направлять на консультацию к психотерапевту или психиатру для подтверждения диагноза депрессии и назначения корректирующей терапии. Именно комплексная терапия данных состояний сможет привести к уменьшению числа госпитализаций, повышению продолжительности и качества жизни пациентов.

\section{Литература:}

1. Вейн А.М., Вознесенская Т.Г., Голубев В.Л, Дюкова Г.М. Депрессия в неврологической практике. Москва «МИА» 2002; 155 с.

2. Депрессивные нарушения у пожилых больных с хронической сердечной недостаточностью И.В. Осипова, Н.В. Погосова, Я.В. Соколова Кардиоваскулярная терапия и профилактика, 2007; 6(6). С. 34-39.

3. Carney R.M., Rich M.W., Freedland K.E., Saini J. et al. Major depressive disorder predicts cardiac events in patients with coronary artery disease // Psychosom. Med. 1988. Vol.50. P.627-633.

4. Pratt L.A., Ford D.E., Crum R.M. et al. Depression, psychotropic medication, and risk of myocardial infarction: prospective data from Baltimore ECA follow-up // Circulation. 1996. N94. P.3123-3129. 